\title{
Band Convergence and Phonon Scattering Mediated Improved Thermoelectric Performance of SnTe-PbTe Nanocomposites
}

Sajid Ahmad ${ }^{1,2}$, Ajay Singh ${ }^{* 2,3}$, Shovit Bhattacharya ${ }^{3}$, M. Navaneethan ${ }^{4}$, Ranita Basu ${ }^{3}$, Ranu Bhatt $^{3}$, Pritam Sarkar ${ }^{3}$, K. N. Meshram ${ }^{3}$, A. K. Debnath ${ }^{3}$, K.P. Muthe ${ }^{3}$, D. K. Aswal ${ }^{3,5}$

${ }^{1}$ Nuclear Research laboratory, Bhabha Atomic Research Centre, Srinagar-190024, India

${ }^{2}$ Homi Bhabha National Institute, Anushaktinagar,Mumbai-400085, India

${ }^{3}$ Technical Physics Division, Bhabha Atomic Research Centre, Mumbai-400085, India

${ }^{4}$ Nanotechnology Research Centre (NRC) \& Department of Physics and Nanotechnology, SRMIST, Chennai-603203, India

${ }^{5}$ CSIR-National Physical Laboratory, K.S. Krishnanan Marg, Pusa, New Delhi-110012, India

\section{Supplementary information}

S1: Table 1: Properties of $(\mathrm{SnTe})_{1-\mathrm{x}}(\mathrm{PbTe})_{\mathrm{x}}(\mathrm{x}=0-0.5)$ samples

\begin{tabular}{lccc}
\hline $\begin{array}{l}\text { Sample } \\
(\text { SnTe })_{1-\mathbf{x}}(\mathbf{P b T e})_{\mathbf{x}}\end{array}$ & Density $\left(\mathbf{g m} / \mathbf{c m}^{3}\right)$ & $\boldsymbol{n ( \mathbf { 1 0 } ^ { \mathbf { 1 9 } } \mathbf { c m } ^ { - 3 } )}$ & $\boldsymbol{m}^{*}\left(\boldsymbol{m}_{\mathbf{e}}\right)$ \\
\hline $\mathrm{x}=0$ & 6.12 & 11 & 0.17 \\
$\mathrm{x}=0.1$ & 6.29 & 8.2 & 0.23 \\
$\mathrm{x}=0.15$ & 6.37 & 6.3 & 0.26 \\
$\mathrm{x}=0.2$ & 6.46 & 5.5 & 0.27 \\
$\mathrm{x}=0.25$ & 6.55 & 5 & 0.29 \\
$\mathrm{x}=0.5$ & 6.96 & 4.8 & 0.29 \\
\hline
\end{tabular}



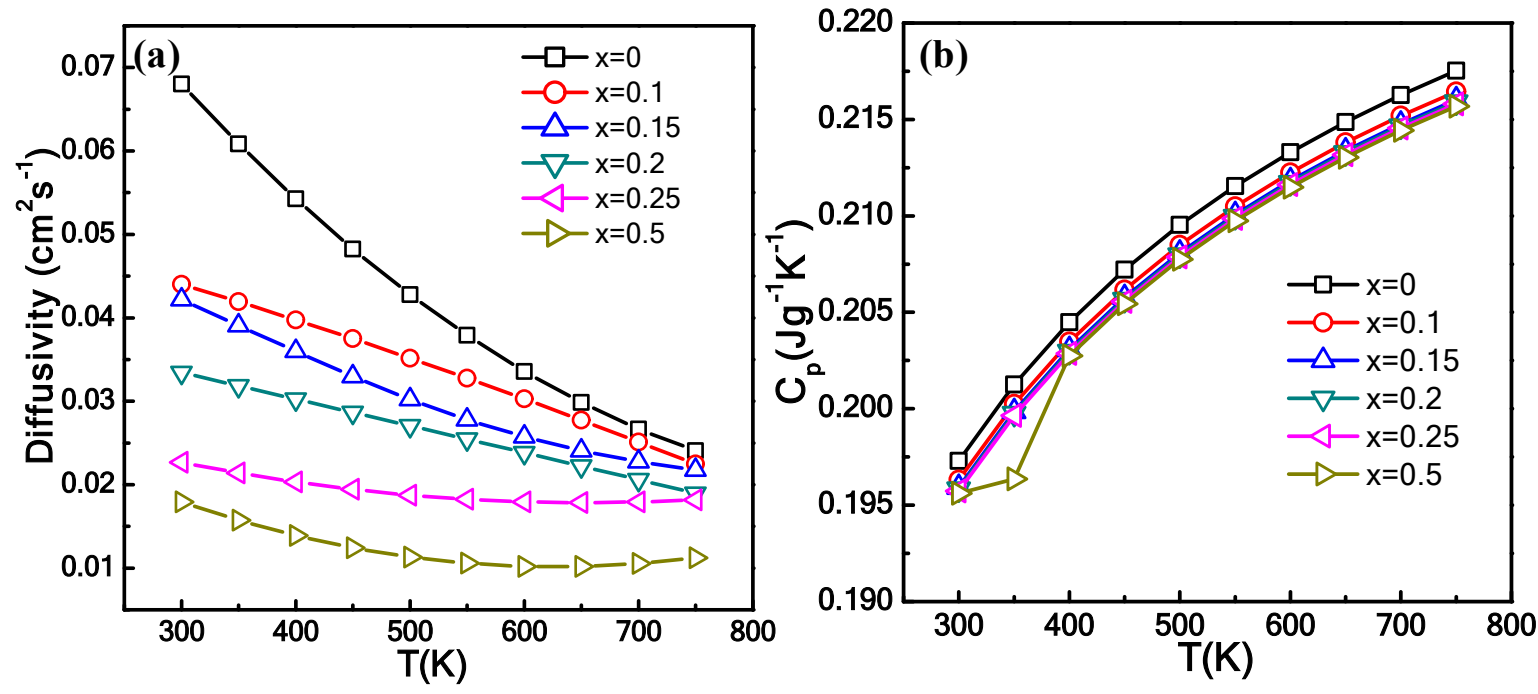

Figure S2: Temperature dependent (a) thermal diffusivity and (b) specific heat data for $(\mathrm{SnTe})_{1-\mathrm{x}}(\mathrm{PbTe})_{\mathrm{x}}(\mathrm{x}=0-0.5)$ samples

S3: Temperature dependence of Lorentz number and electronic thermal conductivity:
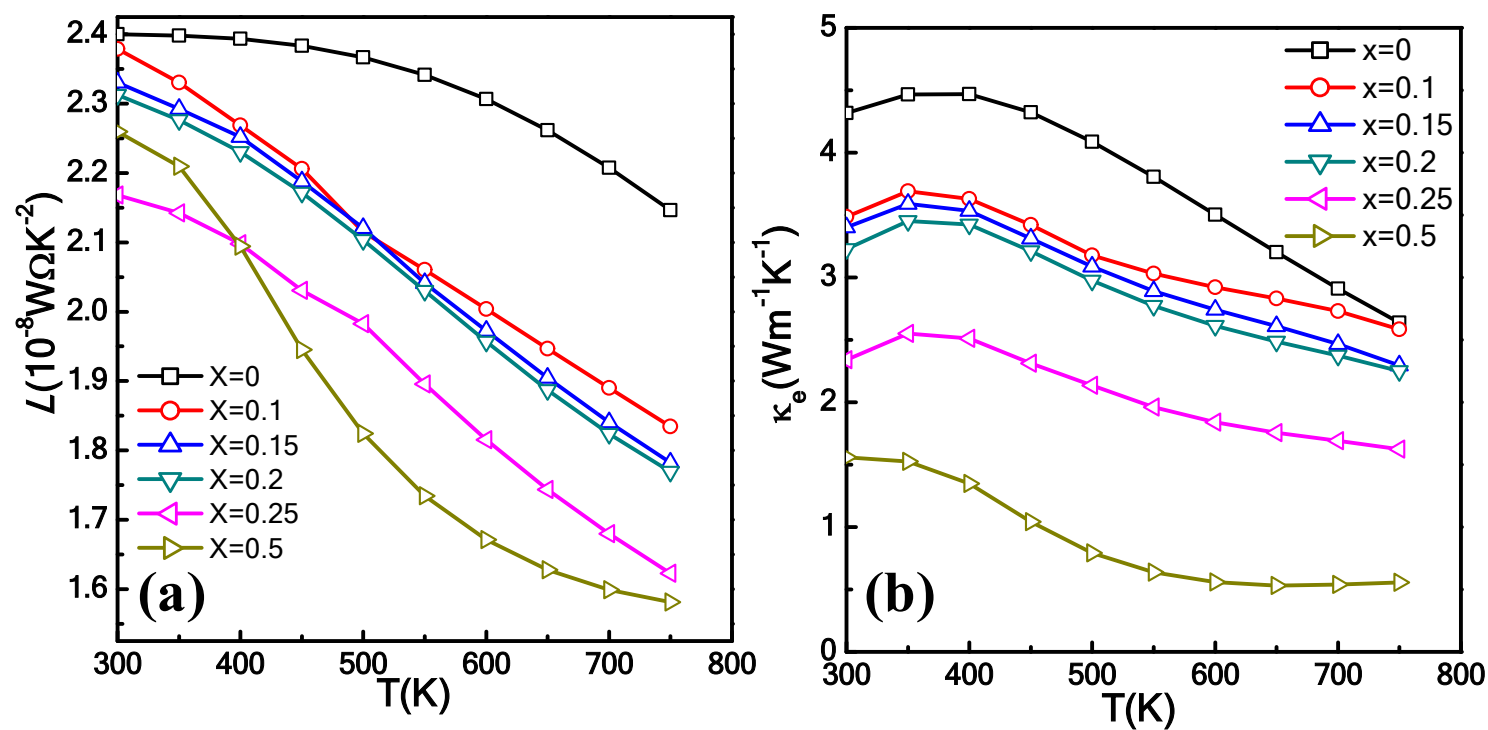

Figure S3: Figure-Temperature dependence of (a) Lorentz number $(L)$ and (b) electronic thermal conductivity $\left(\kappa_{\mathrm{e}}\right)$ 
S4: Work function mapping of $(\mathrm{SnTe})_{1-\mathrm{x}}(\mathrm{PbTe})_{\mathrm{x}}(\mathrm{x}=0-0.5)$ samples:
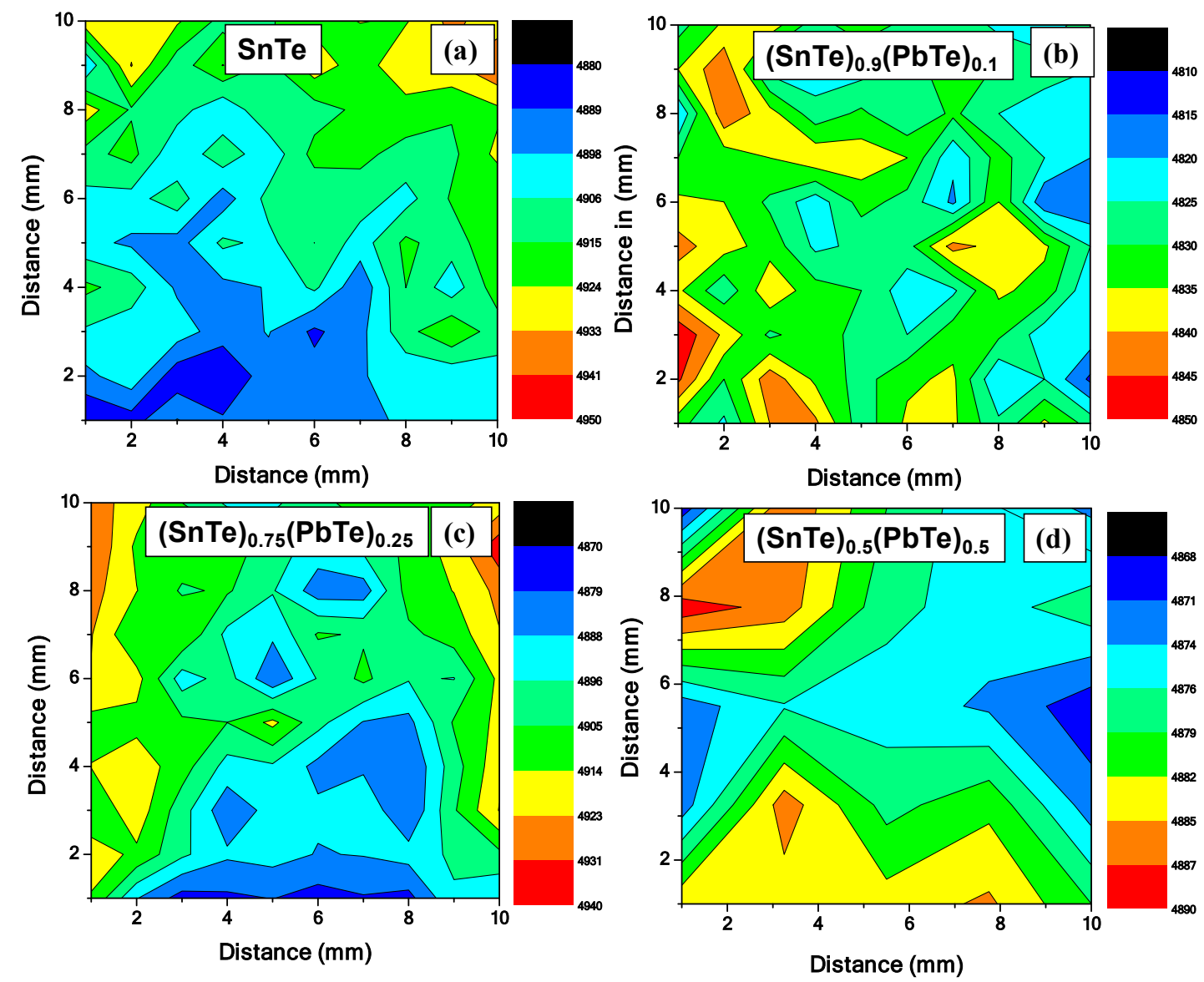

Figure S4: Work function mapping for (a) SnTe (b) $(\mathrm{SnTe})_{0.9}(\mathrm{PbTe})_{0.1}(\mathrm{c})(\mathrm{SnTe})_{0.75}(\mathrm{PbTe})_{0.25}$ and (d) $(\mathrm{SnTe})_{0.5}(\mathrm{PbTe})_{0.5}$. 
S5: Reproducibility of thermoelectric properties of $(\operatorname{SnTe})_{1-\mathrm{x}}(\mathrm{PbTe})_{\mathrm{x}}(\mathrm{x}=0.5)$ sample:
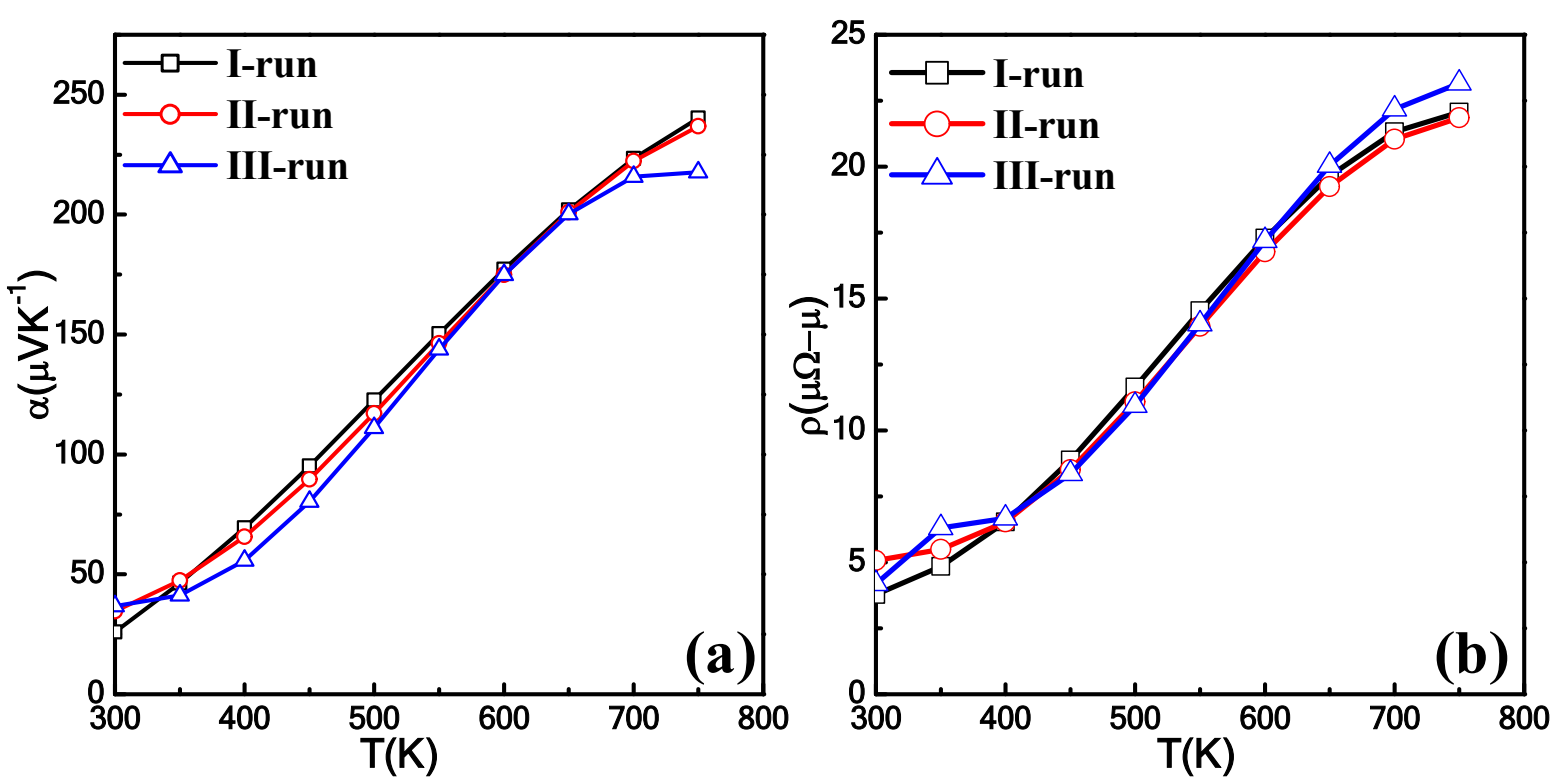

Figure S5: Temperature dependence of (a) Seebeck coefficient (b) Electrical Resistivity of $(\mathrm{SnTe})_{0.5}(\mathrm{PbTe})_{0.5}$ sample at different runs. 
S6: XRD of pure n-type PbTe

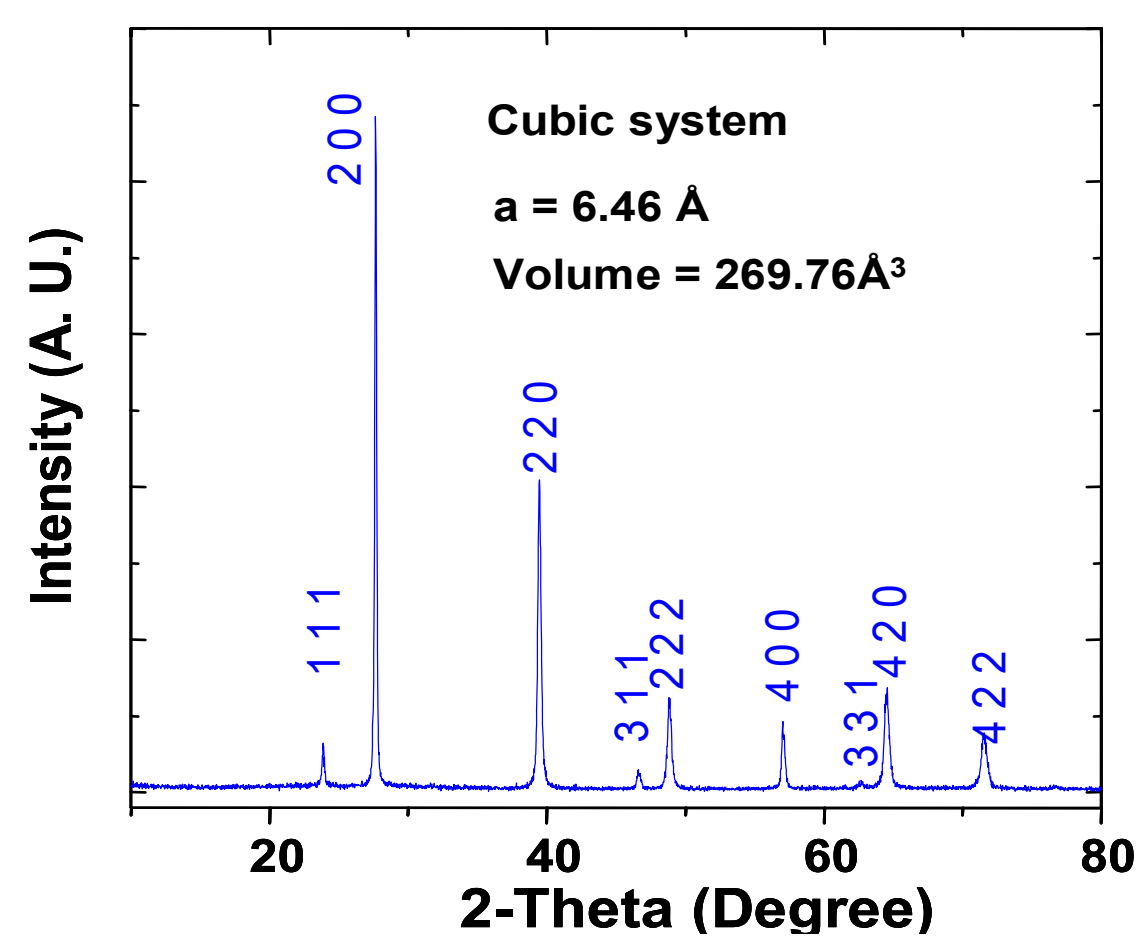

Figure S6: XRD data of n-type PbTe

S7: TEM image of $(\mathrm{SnTe})_{0.5}(\mathrm{PbTe})_{0.5}$ with low magnification

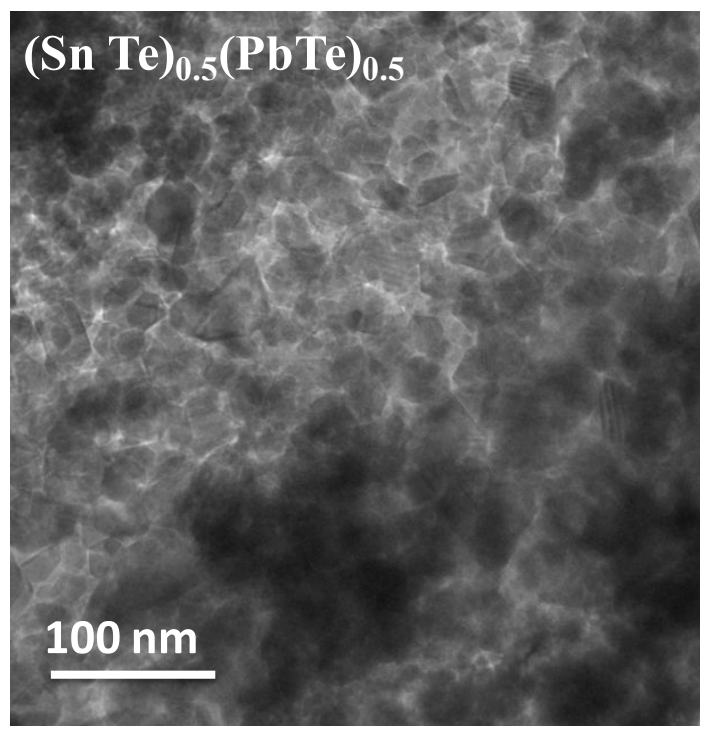

Figure S7: TEM image of $(\mathrm{SnTe})_{0.5}(\mathrm{PbTe})_{0.5}$ sample with low magnification 
S8: TEM image of SnTe and PbTe interface $(\mathrm{SnTe})_{0.5}(\mathrm{PbTe})_{0.5}$ sample

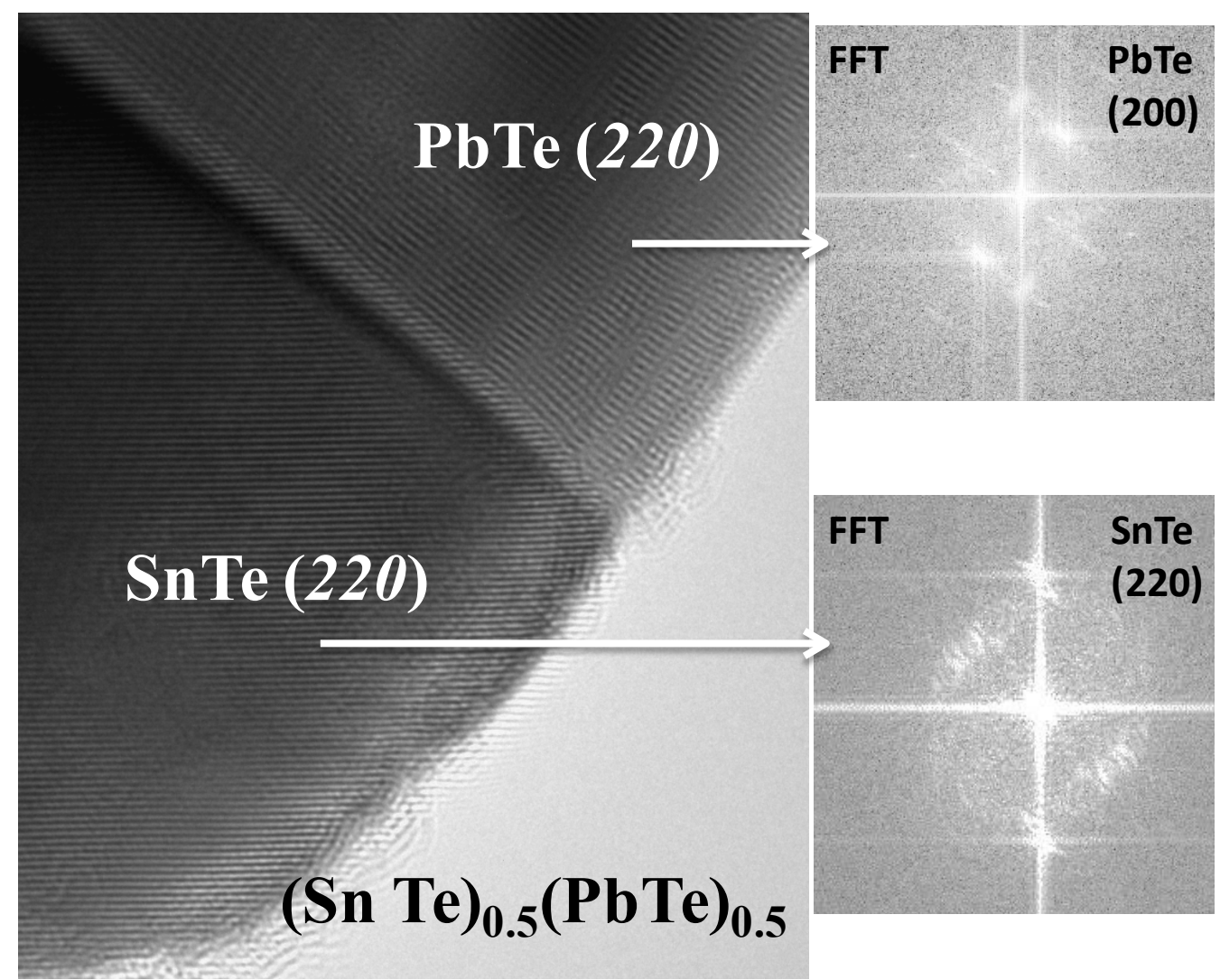

Figure S8: Enlarged view of the $\mathrm{SnTe}$ and $\mathrm{PbTe}$ interface in $(\mathrm{SnTe})_{0.5}(\mathrm{PbTe})_{0.5}$, with corresponding FFT images of SnTe and $\mathrm{PbTe}$ regions 